\title{
Road Noise Levels in Urban Environment Compared to Specification Limits. The Case of the City of Larissa, Greece
}

\author{
Emmanouil A. Papadimitriou ${ }^{1 *}$, Grigorios P. Papageorgiou², Nikolaos Alamanis², \\ Theodosia-Niki Diakosavva ${ }^{*}$

\footnotetext{
1 Program of Civil Engineering T.E., University of Thessaly, Ring Road of Larissa, 41500, Larissa, Greece

2 General Department of Larissa, University of Thessaly, Ring Road of Larissa, 41500, Larissa, Greece

* Corresponding author, e-mail: emmapapa2@uth.gr
}

Received: 18 August 2019, Accepted: 07 June 2020, Published online: 24 July 2020

\begin{abstract}
Greece, as well as other developed countries, is facing the growing problem of road traffic noise. It stands for a severe problem in the urban areas of the country, including the city of Larissa. The root cause is the huge increase in traffic volume and the lack of adequate urban infrastructure planning. Estimation of the level of road traffic noise is usually conducted using acoustic meters. It is widely accepted that most of the cities' population is exposed to high noise levels due to controversial traffic capacity. Moreover, high noise levels are strongly related to phycological and neurological diseases. Thus, it is of utmost importance, the road noise levels to be lower than dictated by relevant specification limits. To develop better noise-environment policies, relative research should focus on the measurement of in-situ noise levels, so as appropriate for each case corrective measures to be taken. The present paper examines the noise levels of a center road of the 5th Greek city, in terms of population, compared to worldwide adopted noise specification limits. The clear aim stands for finding the percentage of road noise that exceeds commonly accepted threshold values, namely limit values of European Union and World Health Organization. The results of this research strongly indicate that measured noise values override upper limit values in a certain extent.
\end{abstract}

Keywords

road noise, noise specification limits, traffic, noise impact, urban environment

\section{Introduction}

Over the last few decades, a large-scale revolution has taken place in the automobile industry, which has led to increased traffic for commercial, professional, personal and tourist purposes. At the same time, since no good pure of evil, it has been observed increase in diseases based on increased noise levels, which come from modern traffic volume. These are psychosomatic diseases that are mainly caused by high levels of noise in urban environments, where there is a high concentration of people and vehicles. Much of this noise is due to the high traffic density observed in modern urban road networks.

Noise is defined as any unwanted sound. This definition is social and differs from the sound without tonality, which is the natural definition of noise. It is a sound derived from anthropogenic activities and is the result of our present mechanized society. Sound is a result of changes in pressure on a propagation medium such as air, which is caused by vibrations or disturbances. Excessive exposure to high noise levels above the permitted limits established by the EU is defined as noise pollution [1]

The generated traffic volume harms the wider urban environment in terms of environmental pollution and noise [2]. In opposition to atmospheric pollution that affects the human body over time, noise is a direct source of nuisance and has direct as well as indirect social effects. High noise levels cause a significant environmental issue because of its impact on human life and health. The negative impact on human health remains a very powerful motivation for research and the most important entrepreneur for taking noise reduction measures.

From the above, it is clear, that it is crucial for the psychosomatic health of city dwellers, the level of traffic noise to be as low as possible. In order to protect the citizens from the aforementioned consequences, specifications 
and regulations have been established worldwide, dictating maximum limits on traffic noise levels. Therefore, the actual noise values should not exceed these limits.

Traffic noise is one of the biggest nuisances faced by people in major cities. This phenomenon, being in the days influenced by the concept of mass globalization, tends to exist not only in large urban centers such as Athens, which gathers $40 \%$ of the population, $50 \%$ of industrial and craft activity, $55 \%$ of the vehicles and $70 \%$ of the services, but also in smaller cities, especially in areas of tourist interest, and in villages throughout the Greek territory [3].

The consequences appear to affect both the quality of the services provided, resulting in a reduction in the tourist flow and the quality of life of the residents in these areas. The Ministry of Environment has incorporated in the $2^{\text {nd }}$ CSF (Community Support Framework), a special noise mitigation project in tourist areas to develop a strategy for the implementation of a package of specific measures and interventions for the environment [4].

Thus, attempts have been made to create forecasting models, taking into account various parameters, traffic load, traffic composition, speed, traffic distribution [2, 4].

It is worth highlighting the fact that noise was not necessarily considered undesirable. It is also documented that for the sake of noise, chaotic systems that self-organize, gain stability and order. It also appears that noise helps build a strong memory in self-organized systems.

The present study deals with the measurement of traffic noise on a road in the center of the $5^{\text {th }}$ in population city of Greece and then analyzes the percentage of noise that is above the limits of applicable standards. In this context, a comparison is made with the marginal values of the relevant specifications of the European Union and the World Health Organization. The goal of the present study is to measure noise levels on a busy road of a large provincial town (5th in terms of population in Greece) on three separate days of the same week, one day, in the beginning, another at the middle and one day at the end of the week. The measurements taken, are related to the same periods accordingly, namely morning, noon and afternoon.

\section{Road noise modeling and measurements}

A road noise modeling used is the sonROAD emission model [5] and the sound propagation model of StL-86 [6]. The sonROAD emission model predicts noise emission as a function of vehicle type, driving speed, slope, and road surface properties. StL-86 accounts for geometrical divergence, air absorption, an idealized ground effect, as well as shielding by obstacles. The reason for using a significantly older (and thus simpler, non-spectral) propagation model was primary due to computational efficiency. To calculate the noise emission with the sonROAD emission model, traffic information such as speed, traffic amount and composition is crucial. However, this monitoring system delivers traffic data for only a very small number of streets, whereas the noise emission model needs traffic volumes and the driven speed of all roads. The most frequently used models for noise exposure assessment, are SoundPLAN [7], CadnaA [8] and TRANEX [9]. HadziNikolova et al. [10] indicated SoundPLAN as a leading environmental noise prediction software. It is a commercial software package offering high-end simulation modules for both air and noise pollution calculations. To calculate road traffic noise, several European modeling methods are implemented in SoundPLAN including e.g., French (NMPB2008) [11], German i.e. RLS90 [12], and several Nordic methods: RTN 96 [13], Nord2000 Road [14]. Bodin et al. [15] used SoundPLAN on a regional scale health-related study in Skåne (Sweden).

Another open-source and more recent model is CNOSSOS-EU [16] that includes several modules for road, railway, aircraft, and industrial noise. CNOSSOS-EU (road module) computes long-term noise $L_{d e n}$ in a similar way as compared to the Nordic noise prediction method Nord2000 Road [14] and differently than TRANEX [9]. CNOSSOS-EU was developed through a Joint Research Center - European Commission project (No. 070307/2008/511090 and 070307/2009/549280) and has been applied at several locations around EU (e.g. The BioShare EU [17]). In contrast to the atmospheric dispersion models, European Commission publications [18] recommend a specific method, the CNOSSOS-EU for the strategic noise mapping (as per the European Noise Directive 2002/49/EC from 2002) and health impact assessment studies.

It is generally accepted that noise is not just a stimulus but a serious health problem [19]. It is worth noting that the following referred are some of the noisiest areas in the world. Calcutta is a huge factory environment in India, and intense shootings due to celebrations ( $>100 \mathrm{~dB})$ make it one of the noisiest areas. Karachi, Pakistan ( $>95 \mathrm{~dB})$, the Mumbai, with nearly 13 million people [19, 20]. Thanks to high traffic and severe overpopulation, it is considered the noisiest city in the world with sound levels that can exceed 100 decibels, also New York (>95 dB) [21]. 
And as cities swell, there are indications that we are having a hard time dealing with noise [21]. In the US, research from 2017 shows that the poorest urban neighborhoods are almost more "polluted" than noise levels by the more affluent areas. In the neighborhoods of Detroit and Chicago, communities with higher proportions of black, Hispanic, and Asian residents have higher noise levels than other neighborhoods [20]. The UN predicts that by 2050 twothirds of people will live in cities. India is expected to have another 416 million urban residents now, with China adding 255 million and Nigeria 189 million [19].

Although noise modeling is widely used by the scientific society worldwide, noise measurements depict the real conditions that is the main objective of this study, along with the percentage of road noise that exceeds allowable limits.

Concluding, emphasis should be placed on the originality of the present paper. Other useful conclusions that distinguish the present work from all those mentioned in the literature are also derived.

\section{Traffic noise impacts}

Road traffic noise is defined as noise production from the movement of motor vehicles to the road surface. Road traffic noise is decreasing throughout the day [22]. In trying to categorize the possible sources of road traffic noise, two dominant categories of vehicles are heavy vehicles, passenger cars, motorcycles, and mopeds.

Also, the exogenous factors that emit noise from vehicles such as horns, stereo entertainment systems, televisors, etc., are key to the quality and ability to disturb road traffic noise.

These exogenous factors are studied as part of the resulting emitted noise and not as individual sources. The propagation takes place through the air, taking into account the state of the propagation medium by calculating physical parameters such as temperature, humidity and geometric amortization due to its distance and angle of measurement. Accordingly, depending on the humidity and temperature values, there is the absorption of the emitted noise from the means of propagation and according to the distance and angle of view of the source-receiver system, the sound decrease is calculated [23].

There are also three effects of human noise taken into account in the design of noise legislation and noise protection measures, which are as follows [24, 25]:

- disturbance from noise

- the difficulty of communication in a noisy environment

- hearing loss
The hearing loss depends cumulatively on the noise level and the duration of exposure. The effects of noise on the body can be classified into [24, 25]:

- effects on hearing

- non-acoustic effects

Non-acoustic effects mainly concern the nervous system, mental functions, circulatory system, human body systems. It is known that workers exposed to noise often experience hypertension, tachycardia, digestive disorders, and difficulty in concentrating, headaches, sleep disorders, fatigue, irritation, hypertension, anxiety as well as gastrointestinal, endocrine and other disturbances in their behavior [26, 27].

Noise affects the central nervous system causing slow reaction time (reflex time) and increased errors. One of the factors that hinder the reduction of discomfort is the fact that in countries with climatic conditions similar to those taking place in Greece several months of the year, activities are being developed in open-air areas, while the windows of the residences often remain open for long throughout the day time-lapses. Another factor is the fact that over the past few years, the noise level emitted by cars has already been decreased by $8 \mathrm{~dB}$ (A) for passenger cars and $15 \mathrm{~dB}$ (A) for lorries throughout highly demanding modern times. Besides, modern and improved types of asphalt result in a $6 \mathrm{~dB}(\mathrm{~A})$ reduction in noise due to friction between the tires and the road [22, 28 and 29].

\section{Noise in the urban environment}

According to the European Union (EU), noise is linked to several health problems, but the number of Europeans exposed to high levels of noise continues to increase. Noise is also harmful to wildlife. EU Member States are required to record noise levels in cities, highways, railroads, and airports and to propose plans to address the problem [29].

Noise from vehicle traffic, industrial and recreational activities is a constantly growing problem. Road traffic is a major source of noise in cities, every day nearly 70 million Europeans in cities are exposed to noise levels above 55 decibels from vehicle traffic alone. According to the World Health Organization (WHO), long-term exposure at such levels may cause increased blood pressure and heart attacks [1, 29].

About 50 million people living in urban areas suffer from excessive noise levels from night traffic and 20 million of them noise from night traffic has a damaging effect on their health [29]. 
Insomnia is the biggest problem. According to the WHO, for a good one-night sleep, continuous background noise should be less than 30 decibels, while individual noise should not exceed 45 decibels [1, 29]. Other effects of noise can be hearing problems, such as tinnitus (sounds made by our body, and the patient listens), mental health problems and anxiety [3].

Problems are also created for birds and animals. While some organizations can adapt to the urban environment, there is concern that noise is likely to divert some of their usual places of reproduction and feeding. Mixing but also the conflict of uses in urban and non-urban environments, on the one hand, gives the image of a full-blown environment, but on the other hand both serious regulatory problems and inadequate administrative control are causing serious noise pollution problems. Depending on the source of noise measures must be taken, but also ways of controlling the level of noise emitted [3].

General categories of noise sources can be considered as:

- airplanes

- trains

- cars - bicycles

- health care facilities (licenses for the development of treadmills in open-air areas, Machine operation)

- manufactures

- commercial Activities (warehousing etc.)

At a more analytical level, the noise is caused by a noise source, continues on a propagation path and ends to the receiver. Noise sources that follow can be considered as the most important sources of noise generation in an urban environment [30]:

- Traffic noise: Noise emitted from vehicle traffic.

- The noise of motorcycles: This is a particular noise phenomenon in Greece. The noise comes from man's intervention in the exhaust pipe of a vehicle.

- Airplane Noise: This is the noise from the active involvement of the various sources of noise associated with the operation of the aircraft during takeoff, flight, and landing.

- Noise from the movement of the fixed track means Trains, Electric Railway, Metro, and Tram.

- Industry, crafts: Noise from the operation of all types of machinery (industries, crafts, printing, steel, alumina, dry cleaners, ventilation and ventilation systems, etc.).

- Noise from other activities: Indicatively, several sources of noise are considered to be particularly disturbing in the urban environment [30]:
- the noise of outdoor units of air conditioners (stationary)

- the noise of construction sites, building

- the noise of washing machines, garages

- noise from automobile stations

- wind noise

- the noise of the city's biological cleaning centers

- the noise of cinemas, gymnasiums, schools

- the noise of sports facilities (ballots, etc.)

- noise from markets (folk markets, open-air pools, etc.)

- noise from alarm and alarm test Areas

- noise from church bells

- airborne or knock-generated noise generated by neighboring activities

Issues of noise are often associated with licensing issues, but mainly with noise control issues or the application of environmental conditions. However, beyond the control and enforcement problems, the current legislative framework is incomplete.

EU legislation obliges authorities to inform the public about the effects of noise pollution and to get citizens' advice on the measures they are planning to address. In this way, the auditors can see if the noise management measures bring about real improvements and approach their elected representatives if necessary [29].

\subsection{Seeking noise levels}

The World Health Organization (WHO) has set specific noise levels to combat traffic noise. These levels refer to the external environmental noise, that is, the noise we measure outside our home. In this way, it is also attempted to protect the external areas of human beings, both in private areas (balcony, private garden) and communal (parks) [32].

The World Health Organization separates the target levels into the following three categories:

(a) Minimum requirements to avoid serious effects on human health. The environmental noise level during the day should not exceed $65 \mathrm{~dB}(\mathrm{~A})$ and $55 \mathrm{~dB}(\mathrm{~A})$ at night.

(b) Average requirements to avoid significant nuisance to human serenity, the daytime environmental noise level should not exceed $55 \mathrm{~dB}(\mathrm{~A})$ and $45 \mathrm{~dB}(\mathrm{~A})$ at night.

(c) Strict requirements for ideal protection in the long term, the intended requirements should be for day 50 $\mathrm{dB}(\mathrm{A})$ and nighttime $40 \mathrm{~dB}(\mathrm{~A})$.

Fig. 1 shows the advantages offered by the location chosen for the installation of the equipment, in terms of the near accesses to that point. 


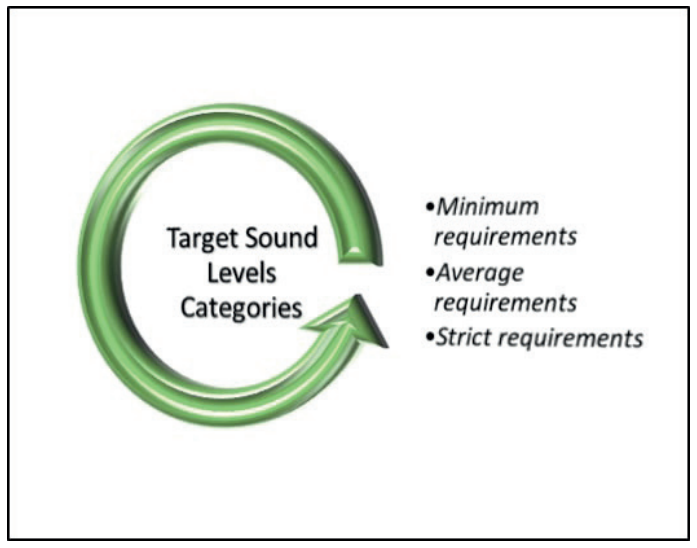

Fig. 1 Target sound levels categories

These levels, of course, are very difficult to achieve, especially in urban centers. However, it is particularly important to pursue such a scenario, as this guarantees the minimization of any problem caused to humans by environmental noise.

\subsection{Maximum traffic noise limits}

According to the EU Directive 2002/49/EC of the European Council, the Council of 25 June 2002 and the CSD 211773/ 2012 Official Gazette: 1367/B'/27.4.2012 "Determination of the Evaluation Indicators and Maximum Allowable Limits of Environmental Noise Indicators from the operation of transport projects, technical specifications of special acoustic studies of calculation and application (EYYY) of noiseless screens, specifications of environmental noise monitoring programs and other provisions" as maximum permissible ceilings for road noise indicators are defined:

- for $L_{d e}$ or $L_{e q}$ index (day-afternoon) $67 \mathrm{~dB}(\mathrm{~A})$

- for $L_{\text {night }}$ index $60 \mathrm{~dB}(\mathrm{~A})$

- for $L_{d e n}$ index $70 \mathrm{~dB}(\mathrm{~A})$

The total disruption index $L_{d e n}$ in decibels $(\mathrm{dB})$ is associated with the $L_{\text {day }}, L_{\text {evening }}, L_{\text {night }}$ indices according to the following equation:

$L_{\text {den }}=10 \log \frac{1}{24}\left(12^{*} 10^{\frac{L_{d a y}}{10}}+4 \cdot 10^{\frac{L_{\text {evening }}+5}{10}}+8 \cdot 10^{\frac{L_{\text {night }}+10}{10}}\right)$.

\section{Experimental process}

The measurements took place in spring 2020 at a selected location of the Other Main Artery "Iroon Polytechniou" in Larissa. Specifically, it is a point from which access to the main road of the city of Larissa is available. In the satellite photo shown below (Fig. 2), the point from which the noise level was measured was given and an overall view of the area of interest of the study is given.

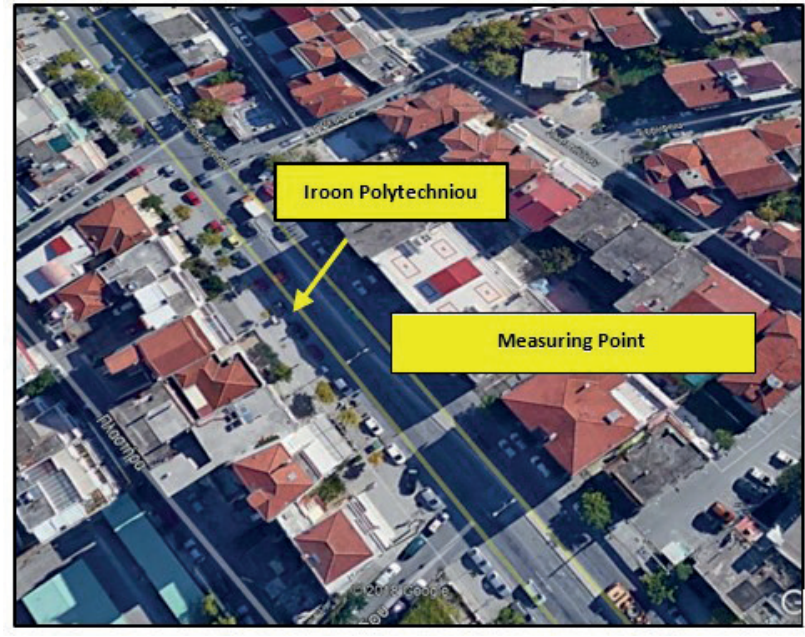

Fig. 2 Satellite picture was taken at the point where the measurements were taken [33]

\subsection{Equipment}

The equipment used at this stage of the study was selected based on a detailed search for the optimal measurement device. The device is displayed in Fig. 3:

This is a US instrument that records the sound pressure level and is designed for audible measurements both for educational purposes and for professionals' occupation, studies of professional interest and use for protection in a noisy working environment. The basic technical features of the extrusion are:

- USB Features for Easy Installation and Data Interface

- data 30 to $130 \mathrm{~dB}$

- Data Recording Capacity up to 129,920 records

- Selecting Data Sample Rate Records real-time clock readings.

- It has two boot methods: programmed (computer) or manual.

- microphone 0.5

- Includes $3.6 \mathrm{~V}$ lithium battery, compatible with Windows ${ }^{\circledR}$ software, USB cover, tripod, USB extension cable and windscreen.

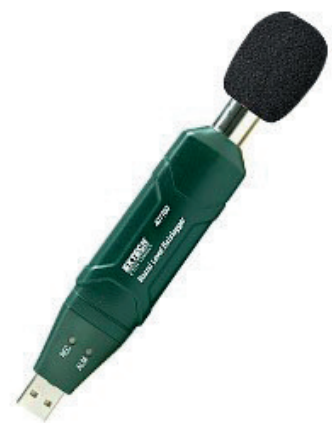

Fig. 3 Extech 407760: USB Sound Level Datalogger (extech.com) [34] 


\subsection{Measurement process}

\subsubsection{Sounder installation}

The sounder was installed at a selected location, mainly on the road and on the facade of Iroon Polytechniou Street, this point was taken at this point because this location has access to the main road and in close distances the existence of bright traffic lights, schools and a plethora of shops is available.

Fig. 4 shows the advantages offered by the location chosen for the installation of the equipment, in terms of the close accesses to that point.

\subsubsection{Measuring instrument measurement - Duration of measurements}

Extech 407760 was used for taking measurements and was defined for the following measurement periods:

- The first measurement took place on Monday 16/03/2020, at 07:26:19-08:26:19, with a total of 721 measurements. Each measurement was taken every $1 \mathrm{sec}$, to 14:12:21-15:12:21 a period of 5 seconds with a total of 721 measurements, each measurement is taken every $2 \mathrm{sec}-$ onds and at 17:51:44-18:51:44, with a total of 721 measurements. Each measurement was taken every $5 \mathrm{sec}$.

- The second measurement took place on Thursday 19/03/2020, at 07:26:19-08:26:19, with a total of 721 measurements. Each measurement was taken every $1 \mathrm{sec}$, to 14:12:21-15:12:21 a period of 5 seconds with a total of 721 measurements, each measurement is taken every 2 seconds and at 17:51:44v18:51:44, with a total of 721 measurements. Each measurement was taken every $5 \mathrm{sec}$.

- The third measurement took place on Sunday 22/03/2020, at 07:26:19-08:26:19, with a total of 721 measurements. Each measurement was taken every $1 \mathrm{sec}$, to 14:12:21-15:12:21 a period of 5 seconds with a total of 721 measurements, each measurement is taken every 2 seconds and at 17:51:44-18:51:44, with a total of 721 measurements. Each measurement was taken every $5 \mathrm{sec}$. The choice of this point has been chosen, as the main interest, in this case, is concentrated on sections of the road which do not include intersections, which require special attention due to the particular conditions prevailing.

\section{Presentation and analysis of results measurement}

Traffic is displayed on Google Maps [33] in different colors. Green means there is no traffic on the road. Orange as traffic is relatively high and red or deep red for traffic congestion.

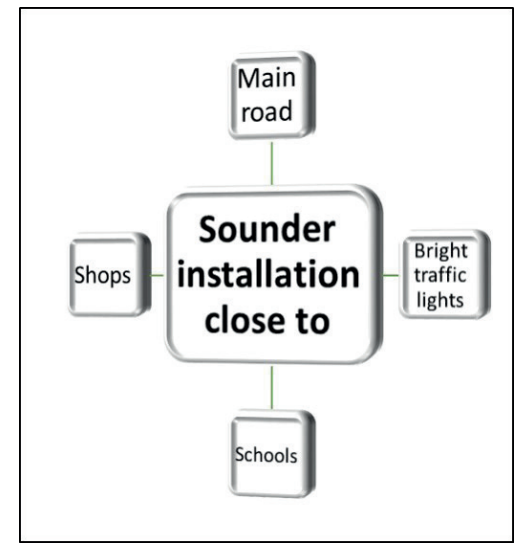

Fig. 4 Advantages of Sounder installation

The main activities in the metered area are in commercial shops and not in industries or handicrafts.

The increased noise levels are due to frequent stops of commercial vehicles and the prevailing traffic due to work transport.

Fig. 5 illustrates the traffic movement at various times studied using Google Maps Traffic.

Figs. 6-14, below show the sound levels over time, individually. The measurements were made at three times a day (morning, midday and afternoon) for three different days in a week. The three different measurements were taken in the exact period, because we need to focus on a result directly interrelated.

Furthermore, the following graphs show the measurements compared to the minimum requirements of $\mathrm{WHO}$ and the limit of Lde. The graphs below show in detail, under the limits of existing legislation, the various noise levels measured for the three-time periods per day of the week.

The horizontal axis shows the measurement time and correspondingly and the vertical axis shows the noise levels recorded by the equipment.

Furthermore, an analysis of the noise level findings is presented in Tables 1-3 below. The tables below, analyze, the percentage $\%$ of measurements exceeding and not exceeding limits, for each day separately, i.e. Monday, Thursday, and Sunday for the respective periods. In conclusion, Table 4 , it appears, the mean value of percentage $\%$ of measurements exceeding / not exceeding limits, by all the days' measurements.

\section{Conclusions}

The present study aimed to investigate the traffic noise in an urban area. The measurements were made in the area of Larissa at "Iroon Polytechniou" Street, showing a 


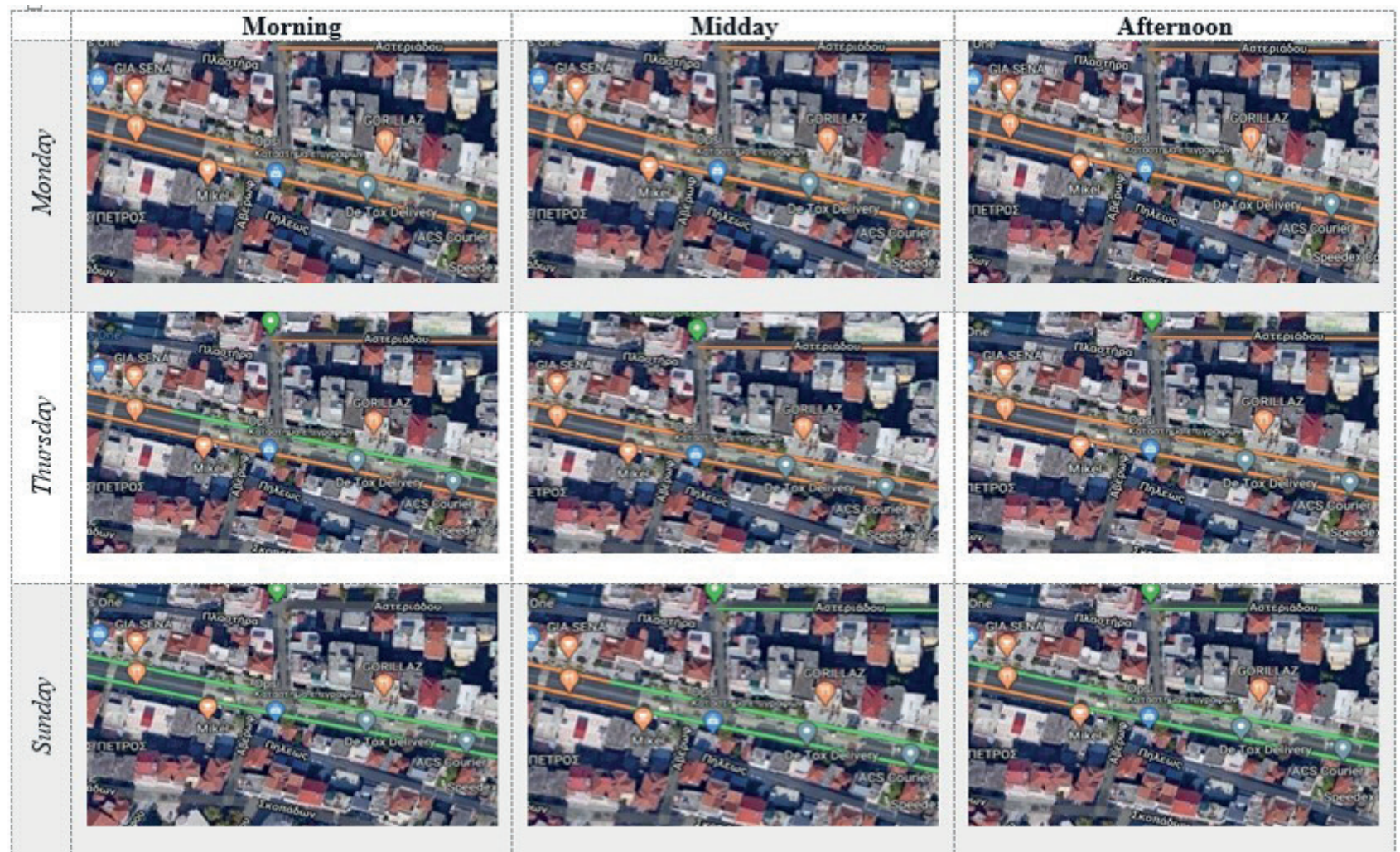

Fig. 5 Visualization of road traffic, according to Google Maps Traffic [33]

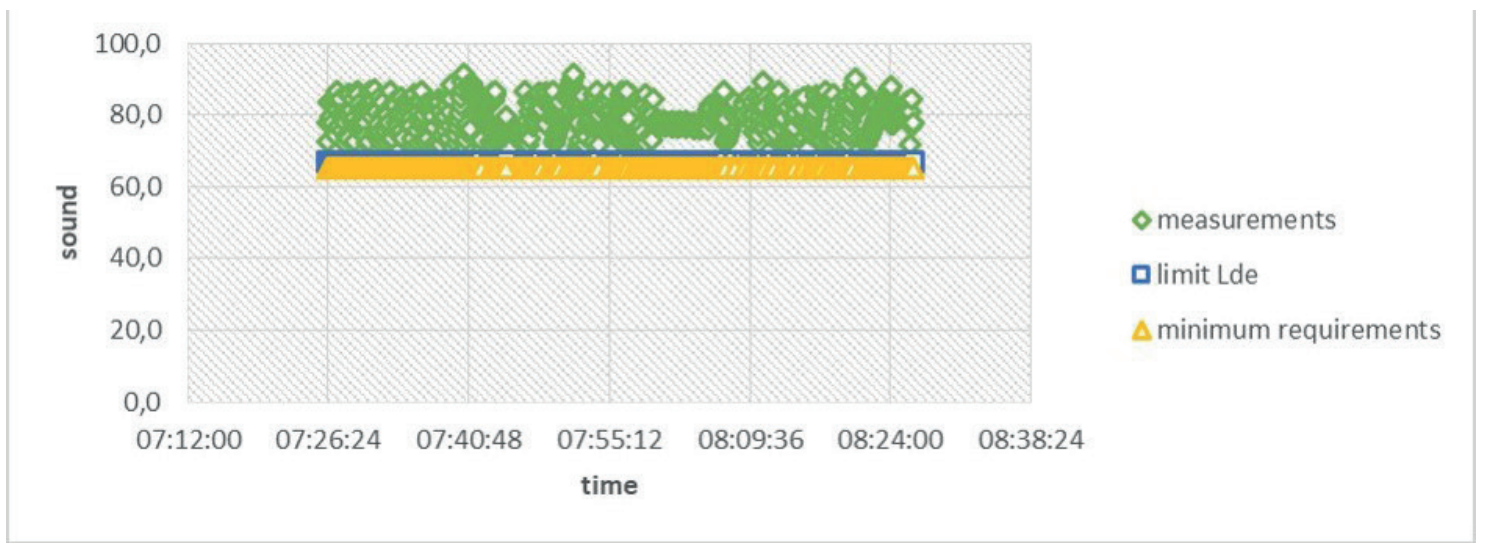

Fig. 6 Morning measurement - Monday

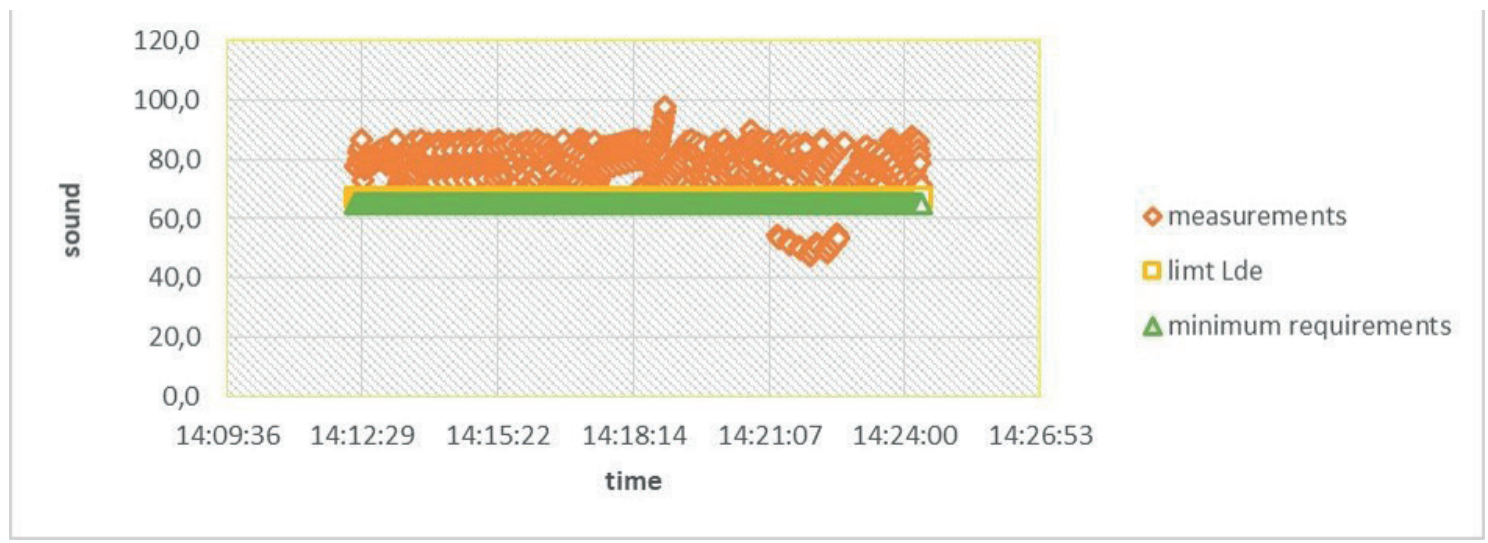

Fig. 7 Midday measurement - Monday 


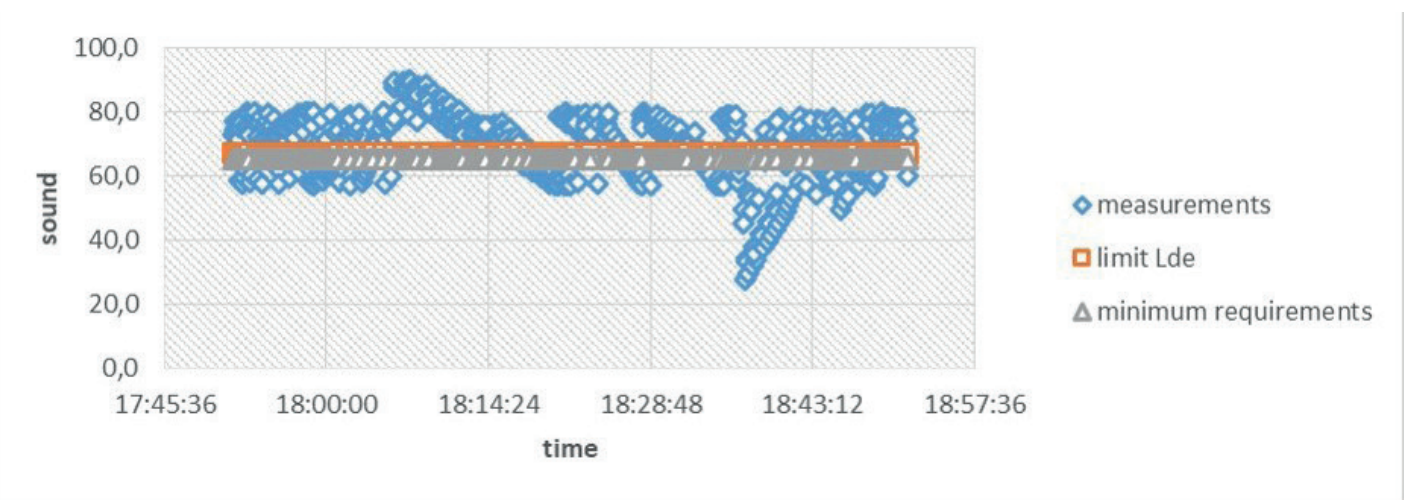

Fig. 8 Afternoon measurement - Monday

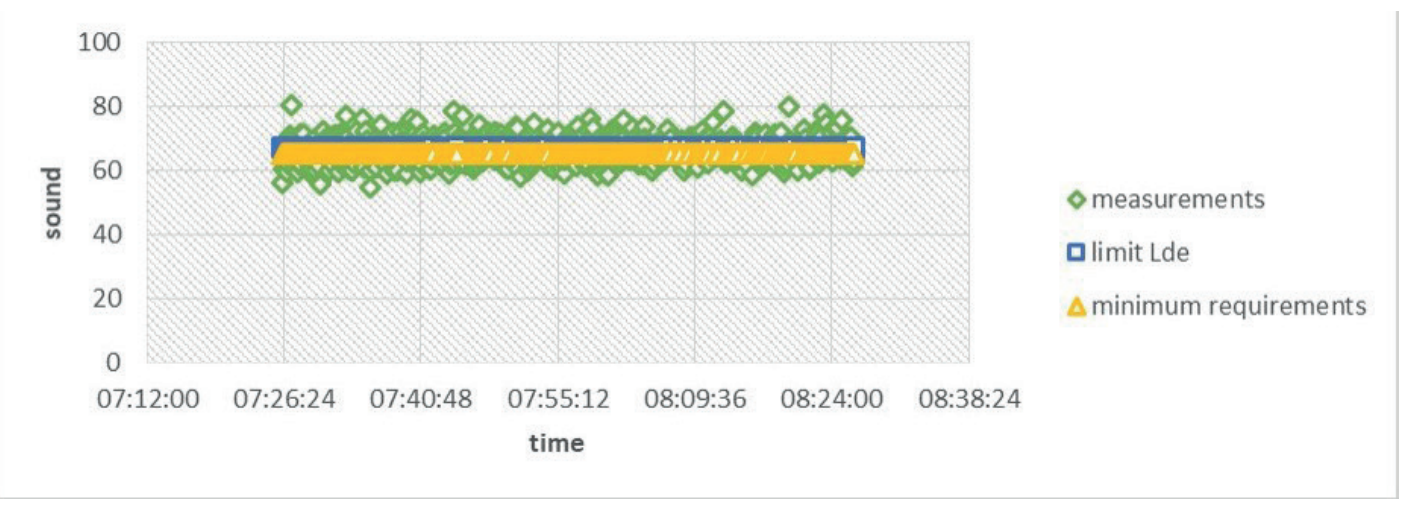

Fig. 9 Morning measurement - Thursday

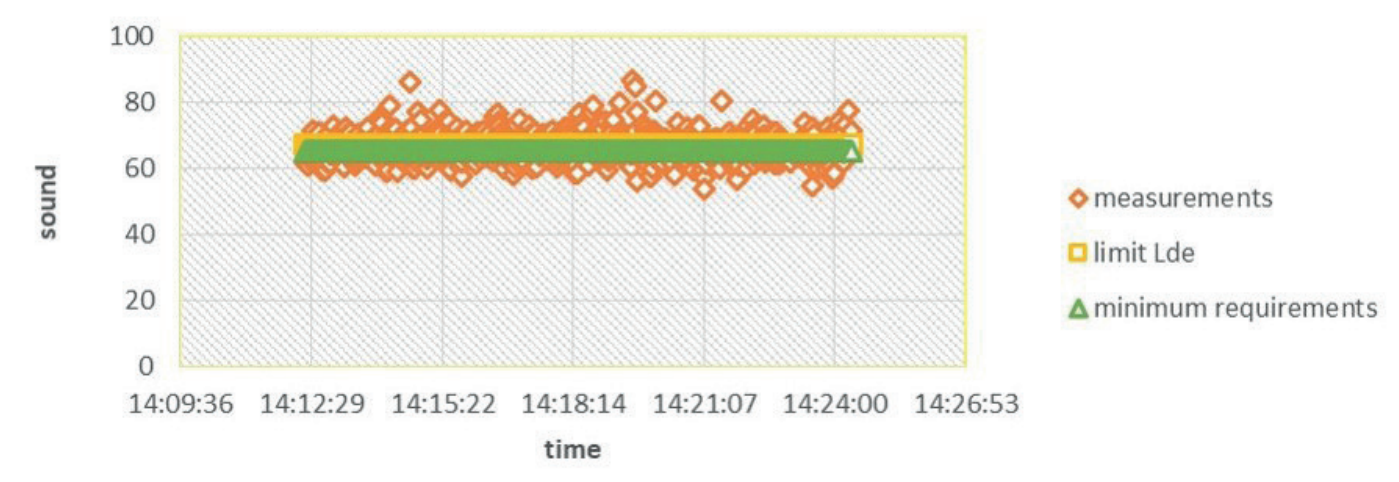

Fig. 10 Midday measurement - Thursday

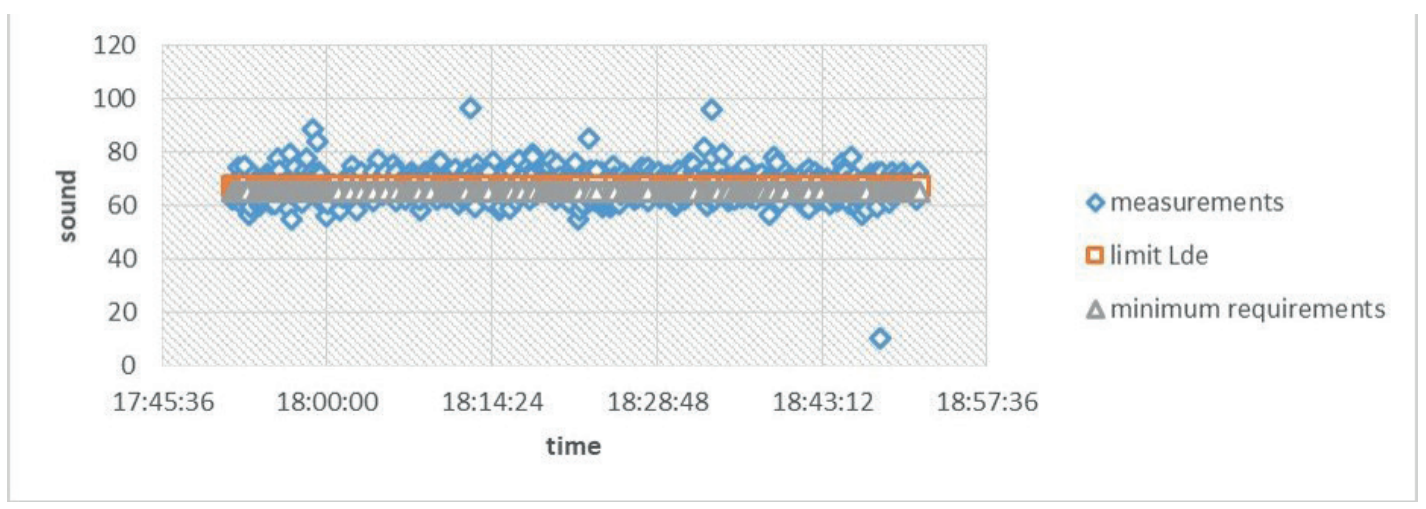

Fig. 11 Afternoon measurement - Thursday 


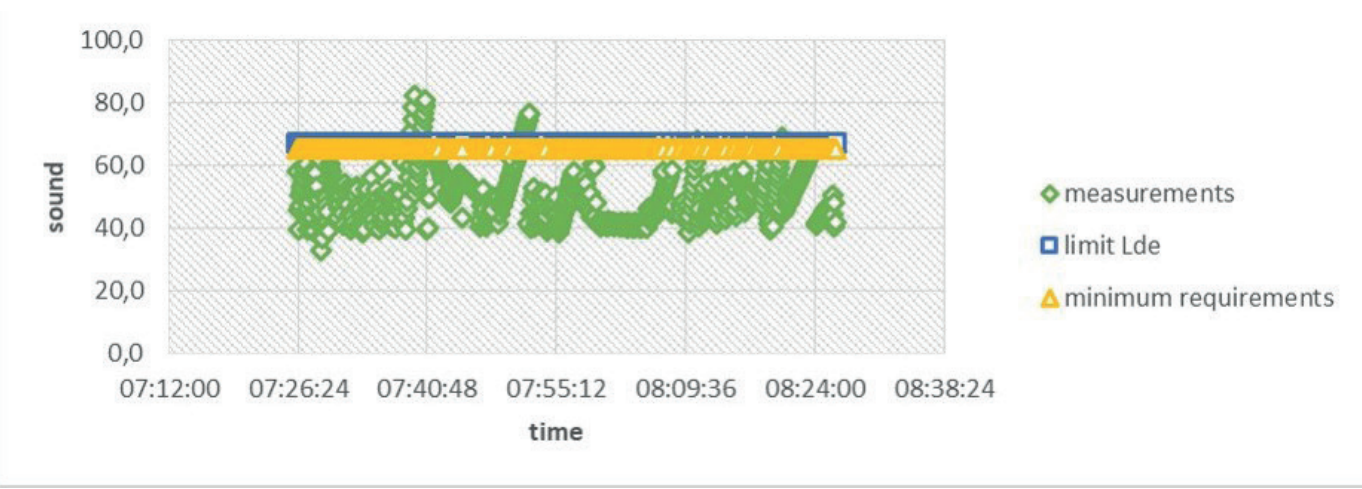

Fig. 12 Morning measurement - Sunday

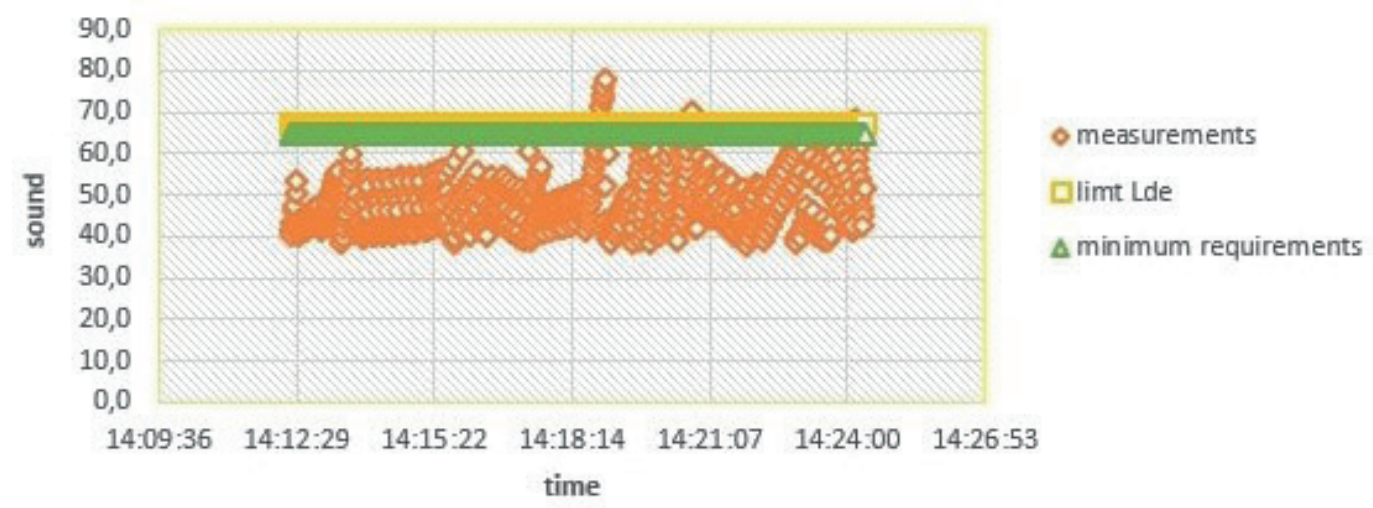

Fig. 13 Midday measurement - Sunday

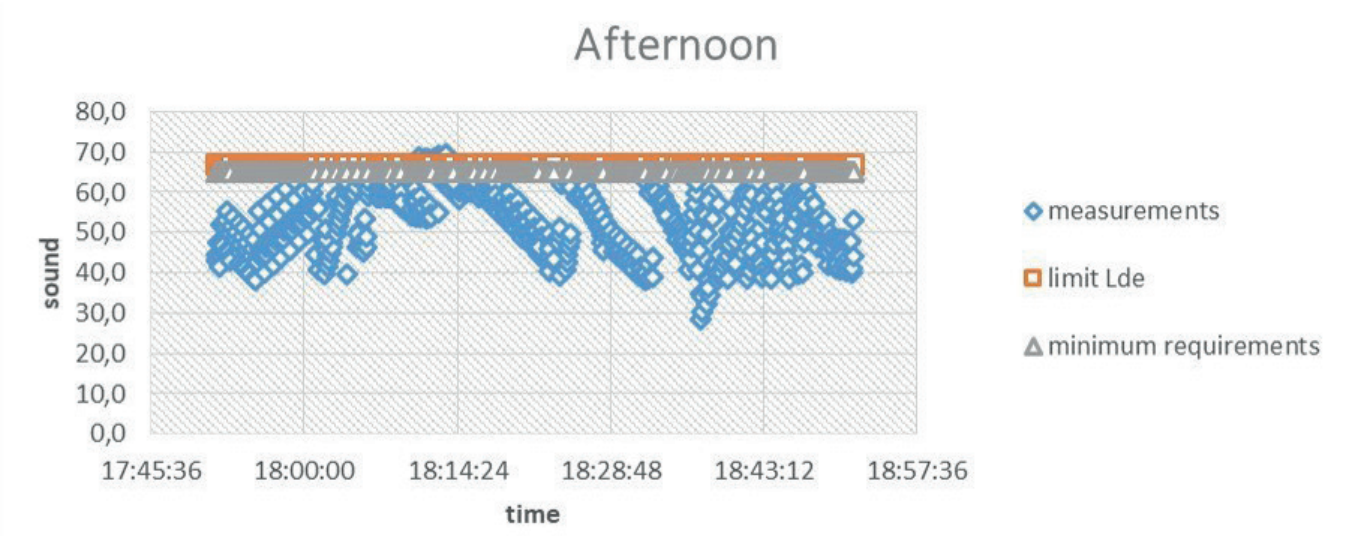

Fig. 14 Afternoon measurement - Sunday

Table 1 Percentage \% of measurements exceeding / not exceeding limits - Monday

\begin{tabular}{lccc}
\hline Percentage \% of measurements: & Morning & Midday & Afternoon \\
\hline Exceeding the $L_{d e}$ index limit & 100 & 95.97 & 65.19 \\
$\begin{array}{l}\text { Not exceeding the } L_{d e} \text { index limit } \\
\begin{array}{l}\text { Exceeding the minimum } \\
\text { requirements of WHO }\end{array}\end{array}$ & 0 & 4.03 & 34.81 \\
$\begin{array}{l}\text { Not exceeding the minimum } \\
\text { requirements of WHO }\end{array}$ & 0 & 95.98 & 69.90 \\
\hline
\end{tabular}

* European Parliament and Council Directive 2002/49 / EC and CSD 211773/2012 Official Gazette: 1367/B'/27.4.2012 - Lde limit 67 (dB),

** World Health Organization Targets - Minimum Day Requirements $65(\mathrm{~dB})$
Table 2 Percentage \% of measurements exceeding / not exceeding limits - Thursday

\begin{tabular}{lccc}
\hline Percentage \% of measurements: & Morning & Midday & Afternoon \\
\hline Exceeding the $L_{d e}$ index limit & 45.49 & 37.73 & 57.42 \\
Not exceeding the $L_{d e}$ index limit & 54.37 & 62.27 & 42.58 \\
$\begin{array}{l}\text { Exceeding the minimum } \\
\text { requirements of WHO }\end{array}$ & 62.83 & 57.42 & 69.63 \\
$\begin{array}{l}\text { Not exceeding the minimum } \\
\text { requirements of WHO }\end{array}$ & 37.17 & 42.58 & 30.37 \\
\hline
\end{tabular}

* European Parliament and Council Directive 2002/49 / EC and CSD 211773/2012 Official Gazette: 1367/B'/27.4.2012 - Lde limit 67 (dB),

** World Health Organization Targets - Minimum Day Requirements $65(\mathrm{~dB})$ 
Table 3 Percentage $\%$ of measurements exceeding / not exceeding limits - Sunday

\begin{tabular}{llll}
\hline Percentage \% of measurements: & Morning & Midday & Afternoon \\
\hline $\begin{array}{l}\text { Exceeding the } L_{d e} \text { index limit } \\
\text { Not exceeding the } L_{d e} \text { index limit }\end{array}$ & 4.16 & 1.39 & 1.39 \\
$\begin{array}{l}\text { Exceeding the minimum } \\
\text { requirements of WHO }\end{array}$ & 5.83 & 1.80 & 2.91 \\
$\begin{array}{l}\text { Not exceeding the minimum } \\
\text { requirements of WHO }\end{array}$ & 94.17 & 98.20 & 97.09 \\
\hline
\end{tabular}

* European Parliament and Council Directive 2002/49/EC and CSD 211773/2012 Official Gazette: 1367/B'/27.4.2012 - Lde limit 67 (dB),

** World Health Organization Targets - Minimum Day Requirements $65(\mathrm{~dB})$

significant overrun during the day (morning, afternoon and afternoon), in terms of the limits established under the EU Directive 2002/49/EC of the European Council, June 2002 and the KYA publication (211773/2012 Official Gazette: 1367/B'/27.4.2012), along with WHO specifications.

As it is perceptible from the results of the measurements presented in this research, a significant percentage of the noise observed on a central road of one of the largest cities

\section{References}

[1] Chialvo, D. R., Cecchi, G. A., Magnasco, M. O. "Noise-induced memory in extended excitable systems", Physical Review E, 61(5), pp. 5654-5657, 2000.

https://doi.org/10.1103/PhysRevE.61.5654

[2] Chatzicocoli, S., Syrakoy, A. C., Syrakos, S. "Urban Development and Health Problems in Greece", presented at UPE8 - Parallel Patterns of Urban Growth and Decline - Sustainability Issues and Challenges for Spatial Planning in the 21st Century Cities and Regions, Kaiserslautern, Germany, March, 23-26, 2009. [in Greek]

[3] Sancho, J. M., Garcia-Ojalvo, J. "Noise-Induced Order in Extended Systems: A Tutorial", In: Freund, J. A., Pöschel, T. (eds.) Stochastic Processes in Physics, Chemistry, and Biology, Springer, Berlin, Heidelberg, Germany, 2000, pp. 235-246. https://doi.org/10.1007/3-540-45396-2_22

[4] Chatzicocoli, S., Syrakos, T. "The need for a healthy city program in Greece. Environment, Health and Sustainable Development", presented at 19th International Association for People-Environment Studies International Conference (IAPS 2006), Alexandria, Egypt, Sept. 11-16, 2006.

[5] Heutschi, K. "SonRoad: New Swiss Road Traffic Noise Model", Acta Acustica united with Acustica, 90(3), pp. 548-554, 2004. [online] Available at: https://www.ingentaconnect.com/contentone/ dav/aaua/2004/00000090/00000003/art00015

[6] BAFU "Computermodell Zur Berechnung von Strassenlaerm, Teil 1, Bedienungsanleitung zum Computerprogramm StL-86" (Computer model for calculating road noise, part 1, operating instructions for the computer program StL-86), Federal Office for the Environment, Bern, Switzerland, Rep. SRU-60-D, 1987. [in German]
Table 4 Mean value of Percentage \% of measurements exceeding / not exceeding limits, by all the days' measurements

\begin{tabular}{lccc}
\hline Percentage \% of measurements: & Morning & Midday & Afternoon \\
\hline Exceeding the $L_{d e}$ index limit & 49.88 & 45.03 & 41.33 \\
Not exceeding the $L_{d e}$ index limit & 50.07 & 54.97 & 58.67 \\
$\quad$ Exceeding the minimum & 56.25 & 51.73 & 47.48 \\
$\quad$ requirements of WHO & & & \\
$\quad \begin{array}{l}\text { Not exceeding the minimum } \\
\text { requirements of WHO }\end{array}$ & 43.78 & 48.27 & 52.52 \\
* & & & \\
European Parliament and Council Directive 2002/49/EC and CSD \\
$211773 / 2012$ Official Gazette: 1367/B'/27.4.2012 - Lde limit 67 (dB), \\
** World Health Organization Targets - Minimum Day Requirements \\
65 (dB)
\end{tabular}

of Greece, is above the limits EU directive has set. This percentage is even more out of thresholds, with regards to WHO regulations.

In order to create a noise map, future research in this field, should be conducted in other Greek cities as well. The main goal of this and future relevant studies, is to lead local authorities to comprehend road noise levels and take mitigation measures responsively.

[7] SoundPLAN "The SoundPLAN Acoustics", [computer program] Available at: https://www.soundplan.eu/en/

[8] DataKustik "CadnaA - state-of-the-art Noise Prediction Software", [computer program] Available at: http://www.datakustik.com/en/ products/cadnaa [Accesed: 19 March 2020]

[9] Gulliver, J., Morley, D., Vienneau, D., Fabbri, F., Bell, M., ... Fecht, D. "Development of an open-source road traffic noise model for exposure assessment", Environmental Modelling \& Software, 74, pp. 183-193, 2015.

https://doi.org/10.1016/j.envsoft.2014.12.022

[10] Hadzi-Nikolova, M., Mirakovski, D., Ristova, E., Ceravolo, S. L. "Modeling and Mapping of Urban Noise Pollution with SoundPLAN Software", International Scientific Journal "Machines, Technologies, Materials", 6, pp. 38-42, 2012.

[11] IFSSTAR "ANNEXES Programme de recherche et de développement DPM/PAPP" (APPENDICES, DPM/PAPP research and development program) (in French) [online] Available at: https://www. ifsttar.fr/fileadmin/redaction/5_ressources-en-ligne/Programme_ de_recherche/Annexes_progr2014_18mars14.pdf

[12] The German Ministry of Economy, Labour, and Housing "Guidelines for noise protection at roads (RLS-90)" [online] Available at: http://www.staedtebauliche-laermfibel.de/?p=100\&p2=3.1.2.4 [Accessed: 19 April 2020]

[13] Nielsen, H. L. "Road Traffic Noise - Nordic Prediction Method", Nordic Council of Ministers, Copenhagen, Denmark, 1996.

[14] Danish Environmental Protection Agency "Nord2000: Nordic noise prediction method" [online] Available at: https://eng.mst.dk/airnoise-waste/noise/traffic-noise/nord2000-nordic-noise-predictionmethod/ [Accessed: 19 March 2020] 
[15] Bodin, T., Björk, J., Mattisson, K., Bottai, M., Rittner, R., Gustavsson, P., Jakobsson, K., Östergren, P.-O., Albin, M. "Road traffic noise, air pollution, and myocardial infarction: a prospective cohort study", International Archives of Occupational and Environmental Health, 89, pp. 793-802, 2016. https://doi.org/10.1007/s00420-016-1115-9

[16] Kephalopoulos, S., Paviotti, M., Anfosso-Ledee, F. "Common Noise Assessment Methods in Europe (CNOSSOS-EU)", Publications Office of the European Union, Luxembourg, Rep. EUR 25379 EN, 2012.

https://doi.org/10.2788/31776

[17] European Commission CORDIS EU research results "Biobank Standardisation and Harmonisation for Research Excellence in the European Union" [online] Available at: https://cordis.europa.eu/ project/id/261433/reporting/en

[18] Kephalopoulos, S., Paviotto, M. "Common Noise Assessment Methods for Europe (CNOSSOS-EU): implementation Challenges in the Context of EU Noise Policy Developments and Future Perspectives" [online] Available at: https://ec.europa.eu/jrc/en/ publication/common-noise-assessment-methods-europe-cnossos-eu-implementation-challenges-context-eu-noise-policy

[19] World Health Organization "Environmental Noise Guidelines for the European Region (2018)" [online] Available at: https://www. euro.who.int/en/health-topics/environment-and-health/noise/ publications/2018/environmental-noise-guidelines-for-theeuropean-region-2018

[20] McMullan, T. "Cities are louder than ever - and it's the poor who suffer most", [online] Available at: https://www.theguardian.com/ cities/2019/apr/25/cities-are-louder-than-ever-and-its-the-poorwho-suffer-most

[21] National Hearing Care "Can you guess the world's noisiest city?" [online] Available at: https://nhc.com.au/blog/worlds-noisest-cities

[22] Vogiatzis, K., Rémy, N. "Changing the Urban Sound Environment in Greece: A Guide Based on Selected Case Studies of Strategic Noise Maps (SNM) and Noise Action Plans (NAP) in Medium and Large Urban Areas", Environments, MDPI, 5(64), Article ID: halshs-01807909, 2018.

https://doi.org/10.3390/environments5060064
[23] SMILE - Sustainable Mobility Initiatives for Local Environment, "Guidelines for Road Traffic Noise Abatement" [pdf] Available at: https://ec.europa.eu/environment/life/project/Projects/index.cfm?fuseaction=home.showFile\&rep=file\&fil=SMILE_guidelines_ noise_en.pdf [Accessed: 8 April 2020]

[24] Knight, R. D. "Physics for Scientists and Engineers: A Strategic Approach with Modern Physics", 4th ed., Pearson, San Francisco, CA, USA, 2016.

[25] Parker, S. P. "McGraw-Hill encyclopedia of physics", McGraw-Hill, New York, NY, USA, 1997.

[26] WHO "Occupational health, A manual for primary health care workers", World Health Organization Regional Office for the Eastern Mediterranean, Cairo, Egypt, 2001. [online] Available at: https://www.who.int/occupational_health/regions/en/oehemhealthcareworkers.pdf?ua=1

[27] Korfali, S. I., Massoud, M. "Assessment of Community Noise Problem in Greater Beirut Area, Lebanon", Environmental Monitoring and Assessment, 84, pp. 203-218, 2003. https://doi.org/10.1023/A:1023322507415

[28] Zannin, P. H. T., Coelho Ferreira, A. M., Szeremetta, B. "Evaluation of Noise Pollution in Urban Parks", Environmental Monitoring and Assessment, 118, pp. 423-43, 2006.

https://doi.org/10.1007/s10661-006-1506-6

[29] European Commission "Noise pollution in the EU" [online] Available at: http:/ec.europa.eu/envi$\mathrm{ronment} / \mathrm{b}$ as ics/he a $1 \mathrm{th}-\mathrm{we} 11 \mathrm{bej} \mathrm{ng} /$ noise/index_en.htm [Accessed: 19 March 2020]

[30] Alton Everest, F. "Master Handbook of Acoustics", Tziolas Publications, Thessaloniki, Greece, 1998.

[31] EUR-Lex "Directive 2002/49/EC of the European Parliament and the Council", [online] Available at: http://eur-lex.europa.eu/ legal-content/EN/TXT/?uri=CELEX:32002L0049

[32] Harnapp, V. R., Noble, A. G. "Noise pollution", GeoJournal, 14, pp. 217-226, 1987. https://doi.org/10.1007/BF00435812

[33] Google Maps "Traffic map of City of Larissa" [online] Available at: https://www.google.gr/maps/@39.6310764,22.4143408,574m/ data $=! 3 \mathrm{~m} 1 ! 1 \mathrm{e} 3 ! 5 \mathrm{~m} 1 ! 1 \mathrm{e} 1 \mathrm{hl}=\mathrm{el}$ [Accessed: 20 March 2020]

[34] Extech "407760: USB Sound Level Datalogger" [online] Available at: http://www.extech.com/products/407760 [Accessed: 20 March 2020] 